\title{
The existence and convergence of best proximity points for generalized proximal contraction mappings
}

\author{
Wutiphol Sintunavarat and Poom Kumam*
}

\section{"Correspondence:}

poom.kum@kmutt.ac.th

Department of Mathematics,

Faculty of Science, King Mongkut's

University of Technology Thonburi,

Bang Mod, Thrung Khru, Bangkok

10140, Thailand

\begin{abstract}
In 2011, Sadiq Basha (Nonlinear Anal. 74:5844-5850, 2011) studied and established best proximity point theorems for proximal contractions of the first and the second kinds which are more general than the fixed point theorems of self-contractions. The purpose of this paper is to extend the notion of proximal contraction mappings of the first and the second kinds. We also establish the existence and convergence of best proximity point theorems for these classes and give an example to validate our main results.
\end{abstract}

MSC: $47 \mathrm{H} 10 ; 47 \mathrm{H} 09$

Keywords: fixed point; best proximity point; proximal contraction mapping of the first kind; proximal contraction mapping of the second kind

\section{Introduction}

Let $X$ be an arbitrary nonempty set. A fixed point for a self-mapping $T: X \rightarrow X$ is a point $x \in X$ such that $T x=x$. The applications of fixed point theory are very important in diverse disciplines of mathematics, statistics, chemistry, biology, computer science, engineering, and economics. One of the very popular tools of fixed point theory is the Banach contraction principle, which first appeared in 1922. It states that if $(X, d)$ is a complete metric space and $T: X \rightarrow X$ is a contraction mapping (i.e., $d(T x, T y) \leq \alpha d(x, y)$ for all $x, y \in X$, where $\alpha \in[0,1))$, then $T$ has a unique fixed point. It has been generalized in different ways by mathematicians over the years (see [1-4]). However, almost all such results relate to the existence of a fixed point for self-mappings.

One of the most interesting studies is the extension of Banach's contraction principle to the case of non-self-mappings. In fact, given nonempty closed subsets $A$ and $B$ of a complete metric space $(X, d)$, a contraction non-self-mapping $T: A \rightarrow B$ does not necessarily have a fixed point.

Eventually, it is quite natural to seek an element $x$ such that $d(x, T x)$ is minimum, which implies that $x$ and $T x$ are in close proximity to each other. As a matter of fact, $d(x, T x)$ is at least $d(A, B)$, and best proximity point theorems accentuate the preceding viewpoint further to guarantee the existence of an element $x$ such that $d(x, T x)$ assumes the least possible value $d(A, B)$, thereby accomplishing the highest possible closeness between $x$ and $T x$. A point $x$ in $A$ for which $d(x, T x)=d(A, B)$ is called a best proximity point of $T$. 
Whenever non-self-mapping $T$ has no fixed point, a best proximity point represents an optimal approximate solution to the equation $T x=x$, for the error involved, $d(x, T x)$, attains the global minimal value $d(A, B)$ for any best proximity point $x$. One finds that best proximity point theorems are natural generalizations of the contraction principle to the case of non-self-mappings because a best proximity point reduces to a fixed point if the underlying mapping is assumed to be self-mapping.

In 1969, a best approximation theorem was introduced by Fan [5]. Afterward, several authors have derived extensions of Fan's theorem in many directions (see, e.g., [6-9]). Other works concerning the existence of a best proximity point theorems for single-valued and set-valued mappings have been established in [10-29].

Recently, Sadiq Basha in [30] gave necessary and sufficient conditions to the claim of the existence of a best proximity point for proximal contractions of the first kind and the second kind which are non-self-mapping analogs of contraction self-mappings and also established some best proximity and convergence theorems. However, the main result of Sadiq Basha [30] is an essential tool to claim the existence of a best proximity point and a sequence that converges to a best proximity point for some non-self-mappings. It is most interesting to find another auxiliary tool for the claim of the existence of a best proximity point and a sequence that converges to this point.

In this work, we introduce a new class of non-self-mappings. Indeed, the classes of proximal contractions of the first kind and the second kind are proper subclasses of these classes. We prove the existence and convergence as regards best proximity point theorems for these classes and also give some illustrative examples of our main results. Our results generalize, extend, and unify several well-known comparable results in the literature and these results can be applied to a much wider class of problems.

\section{Preliminaries}

Throughout this paper, we denote the set of real numbers and the set of positive integers by $\mathbf{R}$ and $\mathbf{N}$, respectively. We also suppose that $A$ and $B$ are nonempty subsets of a metric space $(X, d)$ and use the following notations:

$$
\begin{aligned}
& d(A, B):=\inf \{d(x, y): x \in A \text { and } y \in B\}, \\
& A_{0}:=\{x \in A: d(x, y)=d(A, B) \text { for some } y \in B\}, \\
& B_{0}:=\{y \in B: d(x, y)=d(A, B) \text { for some } x \in A\} .
\end{aligned}
$$

We observe that if $A \cap B \neq \emptyset$, then $A_{0}$ and $B_{0}$ are nonempty. Also, if $A_{0}$ or $B_{0}$ is nonempty, then both $A_{0}$ and $B_{0}$ are nonempty. Further, it is interesting to notice that $A_{0}$ and $B_{0}$ are contained in the boundaries of $A$ and $B$, respectively, provided $A$ and $B$ are closed subsets of a normed linear space such that $d(A, B)>0$.

Definition 1 ([30]) A mapping $S: A \rightarrow B$ is said to be a proximal contraction of the first kind if there exists $\alpha \in[0,1)$ such that

$$
d(a, S x)=d(b, S y)=d(A, B) \quad \Longrightarrow \quad d(a, b) \leq \alpha d(x, y)
$$

for all $a, b, x, y \in A$. 
Clearly, a self-mapping that is a proximal contraction of the first kind is precisely a contraction. However, a non-self proximal contraction is not necessarily a contraction.

Definition 2 ([30]) A mapping $S: A \rightarrow B$ is said to be a proximal contraction of the second kind if there exists $\alpha \in[0,1)$ such that

$$
d(a, S x)=d(b, S y)=d(A, B) \quad \Longrightarrow \quad d(S a, S b) \leq \alpha d(S x, S y)
$$

for all $a, b, x, y \in A$.

The necessary condition for a self-mapping $S$ to be a proximal contraction of the second kind is that

$$
d(S S x, S S y) \leq \alpha d(S x, S y)
$$

for all $x, y$ in the domain of $S$. Therefore, every contraction self-mapping is a proximal contraction of the second kind but the converse is not true (see the example below).

Example 1 Consider $\mathbf{R}$ endowed with the Euclidean metric. Let the self-mapping $S$ : $[0,1] \rightarrow[0,1]$ be defined as

$$
S(x)= \begin{cases}0 & \text { if } x \text { is rational } \\ 1 & \text { otherwise }\end{cases}
$$

Then $S$ is a proximal contraction of the second kind but not a contraction.

The above example shows that a self-mapping that is a proximal contraction of the second kind is not necessarily continuous.

Definition 3 ([30]) Let $S: A \rightarrow B$ and $T: B \rightarrow A$ be two mappings. The pair $(S, T)$ is said to be a proximal cyclic contraction pair if there exists $\alpha \in[0,1)$ such that

$$
d(a, S x)=d(b, T y)=d(A, B) \quad \Longrightarrow \quad d(a, b) \leq \alpha d(x, y)+(1-\alpha) d(A, B)
$$

for all $a, b, x, y \in A$.

Definition 4 ([30]) Let $S: A \rightarrow B$ be a mapping and $g: A \rightarrow A$ be an isometry. The mapping $S$ is said to preserve the isometric distance with respect to $g$ if

$$
d(\operatorname{Sgx}, \operatorname{Sgy})=d(S x, S y)
$$

for all $x, y \in A$.

Definition 5 ([30]) A point $x \in A$ is said to be a best proximity point of the mapping $S: A \rightarrow B$ if it satisfies the condition that

$$
d(x, S x)=d(A, B)
$$


It can be observed that a best proximity reduces to a fixed point if the underlying mapping is a self-mapping.

Definition 6 ([30]) $A$ is said to be approximatively compact with respect to $B$ if every sequence $\left\{x_{n}\right\}$ in $A$ that satisfies the condition that $d\left(y, x_{n}\right) \rightarrow d(y, A)$ for some $y \in B$ has a convergent subsequence.

We observe that every set is approximatively compact with respect to itself, and that every compact set is approximatively compact. Moreover, $A_{0}$ and $B_{0}$ are nonempty sets if $A$ is compact and $B$ is approximatively compact with respect to $A$.

\section{Main results}

For mappings $S: A \rightarrow B$ and $g: A \rightarrow A \cup B$, we let $\Xi_{S}(g)$ be a collection of mappings $\xi_{S}: A \rightarrow[0,1)$ which satisfies the following condition:

$$
d(g x, S y)=d(A, B) \quad \Longrightarrow \quad \xi_{S}(x) \leq \xi_{S}(y)
$$

for $x, y \in A$.

Definition 7 A mapping $S: A \rightarrow B$ is said to be a generalized proximal contraction of the first kind with respect to $g: A \rightarrow A \cup B$ if there exists a mapping $\xi_{S} \in \Xi_{S}(g)$ such that

$$
d(a, S x)=d(b, S y)=d(A, B) \quad \Longrightarrow \quad d(a, b) \leq \xi_{S}(x) d(x, y)
$$

for all $a, b, x, y \in A$.

It is easy to see that a generalized proximal contraction of the first kind with respect to the mapping $g$ reduces to proximal contraction of the first kind if we set $\xi_{S}(x)=\alpha$ for all $x \in A$ where $\alpha \in[0,1)$. But the converse is not true (see the example below).

Example 2 Consider the metric space $\mathbf{R}^{n}$ with Euclidean metric, where $n \in \mathbf{N}$. Let

$$
A=\left\{(y, 0, \pi, \pi, \ldots, \pi) \in \mathbf{R}^{n}:-1<y<1\right\}
$$

and

$$
B=\left\{(y, 1, \pi, \pi, \ldots, \pi) \in \mathbf{R}^{n}:-1<y<1\right\} .
$$

Define two mappings $S: A \rightarrow B$ and $g: A \rightarrow A \cup B$ as follows:

$$
S(y, 0, \pi, \pi, \ldots, \pi)=\left(\frac{y^{2}}{2}, 1, \pi, \pi, \ldots, \pi\right)
$$

and

$$
g(y, 0, \pi, \pi, \ldots, \pi)=(-y, 0, \pi, \pi, \ldots, \pi) .
$$

Then it is easy to see that $d(A, B)=1$. 
It is easy to show that there is no $\alpha \in[0,1)$ that satisfies

$$
d(a, S x)=d(b, S y)=d(A, B) \quad \Longrightarrow \quad d(a, b) \leq \alpha d(x, y)
$$

for all $a, b, x, y \in A$. Therefore, $S$ is not a proximal contraction of the first kind.

Next, we show that $S$ is a generalized proximal contraction of the first kind with respect to $g$. Consider a function $\xi_{S}: A \rightarrow[0,1)$ defined by

$$
\xi_{S}(y, 0, \pi, \pi, \ldots, \pi)=\frac{|y|+1}{2} .
$$

It is easy to see that $\xi_{S} \in \Xi_{S}(g)$.

If $\left(y_{1}, 0, \pi, \pi, \ldots, \pi\right),\left(y_{2}, 0, \pi, \pi, \ldots, \pi\right) \in A$ such that

$$
d\left(a, S\left(y_{1}, 0, \pi, \pi, \ldots, \pi\right)\right)=d(A, B)=1
$$

and

$$
d\left(b, S\left(y_{2}, 0, \pi, \pi, \ldots, \pi\right)\right)=d(A, B)=1
$$

for all $a, b \in A$, then we have

$$
a=\left(\frac{y_{1}^{2}}{2}, 0, \pi, \pi, \ldots, \pi\right), \quad b=\left(\frac{y_{2}^{2}}{2}, 0, \pi, \pi, \ldots, \pi\right) .
$$

Therefore, it follows that

$$
\begin{aligned}
d(a, b) & =d\left(\left(\frac{y_{1}^{2}}{2}, 0, \pi, \pi, \ldots, \pi\right),\left(\frac{y_{2}^{2}}{2}, 0, \pi, \pi, \ldots, \pi\right)\right) \\
& =\left|\frac{y_{1}^{2}}{2}-\frac{y_{2}^{2}}{2}\right| \\
& =\left(\frac{\left|y_{1}+y_{2}\right|}{2}\right)\left|y_{1}-y_{2}\right| \\
& \leq\left(\frac{\left|y_{1}\right|+\left|y_{2}\right|}{2}\right)\left|y_{1}-y_{2}\right| \\
& \leq\left(\frac{\left|y_{1}\right|+1}{2}\right)\left|y_{1}-y_{2}\right| \\
& =\xi_{S}\left(y_{1}, 0, \pi, \pi, \ldots, \pi\right) d\left(\left(y_{1}, 0, \pi, \pi, \ldots, \pi\right),\left(y_{2}, 0, \pi, \pi, \ldots, \pi\right)\right) .
\end{aligned}
$$

This implies that the non-self-mapping $S$ is a generalized proximal contraction of the first kind with respect to $g$ with the function $\xi_{S}$.

Definition 8 A mapping $S: A \rightarrow B$ is said to be a generalized proximal contraction of the second kind with respect to $g: A \rightarrow A \cup B$ if there exists a mapping $\xi_{S} \in \Xi_{S}(g)$ such that

$$
d(a, S x)=d(b, S y)=d(A, B) \quad \Longrightarrow \quad d(S a, S b) \leq \xi_{S}(x) d(S x, S y)
$$

for all $a, b, x, y \in A$. 
Remark 1 The class of generalized proximal contractions of the second kind with respect to $g$ is more general than the class of proximal contractions of the second kind (Definition 2).

Next, we give the result for generalized proximal contractions of the first kind.

Theorem 1 Let $(X, d)$ be a complete metric space and $A$ and $B$ be nonempty, closed subsets of $X$. Further, suppose that $A_{0}$ or $B_{0}$ is nonempty. Let $S: A \rightarrow B, T: B \rightarrow A$ and $g: A \cup B \rightarrow$ $A \cup B$ satisfy the following conditions:

(a) $S$ is a generalized proximal contractions of the first kind with respect to $\left.g\right|_{A}$ and $T$ is a generalized proximal contractions of the first kind with respect to $\left.g\right|_{B}$.

(b) $g$ is an isometry.

(c) The pair $(S, T)$ is a proximal cyclic contraction.

(d) $S\left(A_{0}\right) \subseteq B_{0}, T\left(B_{0}\right) \subseteq A_{0}$.

(e) $A_{0} \subseteq g\left(A_{0}\right)$ and $B_{0} \subseteq g\left(B_{0}\right)$.

Then there exists a unique point $x \in A$ and there exists a unique point $y \in B$ such that

$$
d(g x, S x)=d(g y, T y)=d(x, y)=d(A, B) .
$$

Moreover, for any fixed $x_{0} \in A_{0}$, the sequence $\left\{x_{n}\right\}$, defined by

$$
d\left(g x_{n}, S x_{n-1}\right)=d(A, B)
$$

converges to the element $x$. For any fixed $y_{0} \in B_{0}$, the sequence $\left\{y_{n}\right\}$, defined by

$$
d\left(g y_{n}, T y_{n-1}\right)=d(A, B)
$$

converges to the element $y$.

Furthermore, a sequence $\left\{u_{n}\right\}$ in A converges to $x$ if $\left\{\xi_{s}\left(x_{n}\right): n \in \mathbf{N}\right\}$ is bounded with constant $M<1$ and there is a sequence of positive numbers $\left\{\epsilon_{n}\right\}$ such that

$$
\lim _{n \rightarrow \infty} \epsilon_{n}=0 \quad \text { and } \quad d\left(u_{n+1}, z_{n+1}\right) \leq \epsilon_{n},
$$

where $z_{n+1} \in A$ satisfies the condition that $d\left(g z_{n+1}, S u_{n}\right)=d(A, B)$.

Proof Let $x_{0}$ be a fixed element in $A_{0}$. In view of the fact that $S\left(A_{0}\right) \subseteq B_{0}$ and $A_{0} \subseteq g\left(A_{0}\right)$, it is ascertained that there exists an element $x_{1} \in A_{0}$ such that

$$
d\left(g x_{1}, S x_{0}\right)=d(A, B) .
$$

Again, since $S\left(A_{0}\right) \subseteq B_{0}$ and $A_{0} \subseteq g\left(A_{0}\right)$, there exists an element $x_{2} \in A_{0}$ such that

$$
d\left(g x_{2}, S x_{1}\right)=d(A, B)
$$

This process can be continued. Therefore, we can construct the sequence $\left\{x_{n}\right\}$ in $A_{0}$ such that

$$
d\left(g x_{n}, S x_{n-1}\right)=d(A, B)
$$

for all $n \in \mathbf{N}$. 
It follows from $S$ being a generalized proximal contraction of the first kind with respect to $\left.g\right|_{A}$ that

$$
d\left(g x_{n+1}, g x_{n}\right) \leq \xi_{S}\left(x_{n}\right) d\left(x_{n}, x_{n-1}\right)
$$

for all $n \in \mathbf{N}$. Since $g$ is an isometry, we have

$$
d\left(x_{n+1}, x_{n}\right) \leq \xi_{S}\left(x_{n}\right) d\left(x_{n}, x_{n-1}\right)
$$

for all $n \in \mathbf{N}$. From (3) and the notion of a generalized proximal contraction of the first kind with respect to $\left.g\right|_{A}$, we get

$$
\begin{aligned}
d\left(x_{n+1}, x_{n}\right) \leq & \xi_{S}\left(x_{n}\right) d\left(x_{n}, x_{n-1}\right) \\
\leq & \xi_{S}\left(x_{n-1}\right) d\left(x_{n}, x_{n-1}\right) \\
\leq & \xi_{S}\left(x_{n-2}\right) d\left(x_{n}, x_{n-1}\right) \\
& \vdots \\
\leq & \xi_{S}\left(x_{0}\right) d\left(x_{n}, x_{n-1}\right)
\end{aligned}
$$

for all $n \in \mathbf{N}$. By repeating (6), we get

$$
d\left(x_{n+1}, x_{n}\right) \leq \zeta^{n} d\left(x_{1}, x_{0}\right)
$$

for all $n \in \mathbf{N}$, where $\zeta=\xi_{S}\left(x_{0}\right) \in[0,1)$. For positive integers $m$ and $n$ with $n>m$, it follows from (7) that

$$
\begin{aligned}
d\left(x_{n}, x_{m}\right) & \leq d\left(x_{n}, x_{n-1}\right)+d\left(x_{n-1}, x_{n-2}\right)+\cdots+d\left(x_{m+1}, x_{m}\right) \\
& \leq \zeta^{n-1} d\left(x_{1}, x_{0}\right)+\zeta^{n-2} d\left(x_{1}, x_{0}\right)+\cdots+\zeta^{m} d\left(x_{1}, x_{0}\right) \\
& \leq\left(\frac{\zeta^{m}}{1-\zeta}\right) d\left(x_{1}, x_{0}\right),
\end{aligned}
$$

which implies that $d\left(x_{n}, x_{m}\right) \rightarrow 0$ as $m, n \rightarrow \infty$ and then $\left\{x_{n}\right\}$ is a Cauchy sequence in $A$. By the completeness of $A$, the sequence $\left\{x_{n}\right\}$ converges to some $x \in A$.

Similarly, in view of the fact that $T\left(B_{0}\right) \subseteq A_{0}$ and $A_{0} \subseteq g\left(A_{0}\right)$, we can conclude that, for fixed $y_{0} \in B_{0}$, there is a sequence $\left\{y_{n}\right\}$ in $B$ such that

$$
d\left(g y_{n}, T y_{n-1}\right)=d(A, B)
$$

for all $n \in \mathbf{N}$. Since $T$ is a generalized proximal contraction of the first kind with respect to $\left.g\right|_{B}$, we have

$$
d\left(g y_{n+1}, g y_{n}\right) \leq \xi_{T}\left(y_{n}\right) d\left(y_{n}, y_{n-1}\right)
$$

From $g$ being an isometry, we get

$$
d\left(y_{n+1}, y_{n}\right) \leq \xi_{T}\left(y_{n}\right) d\left(y_{n}, y_{n-1}\right)
$$


for all $n \in \mathbf{N}$. By virtue of (9) and $T$ being a generalized proximal contraction of the first kind with respect to $\left.g\right|_{B}$, we get

$$
\begin{aligned}
d\left(x_{n+1}, y_{n}\right) \leq & \xi_{T}\left(y_{n}\right) d\left(y_{n}, y_{n-1}\right) \\
\leq & \xi_{T}\left(y_{n-1}\right) d\left(y_{n}, y_{n-1}\right) \\
\leq & \xi_{T}\left(y_{n-2}\right) d\left(y_{n}, y_{n-1}\right) \\
& \vdots \\
\leq & \xi_{T}\left(y_{0}\right) d\left(y_{n}, y_{n-1}\right)
\end{aligned}
$$

for all $n \in \mathbf{N}$. By repeating (12), we get

$$
d\left(y_{n+1}, y_{n}\right) \leq \eta^{n} d\left(y_{1}, y_{0}\right)
$$

for all $n \in \mathbf{N}$, where $\eta=\xi_{T}\left(y_{0}\right) \in[0,1)$. For positive integers $m$ and $n$ with $n>m$, it follows from (13) that

$$
\begin{aligned}
d\left(y_{n}, y_{m}\right) & \leq d\left(y_{n}, y_{n-1}\right)+d\left(y_{n-1}, y_{n-2}\right)+\cdots+d\left(y_{m+1}, y_{m}\right) \\
& \leq \eta^{n-1} d\left(y_{1}, y_{0}\right)+\eta^{n-2} d\left(y_{1}, y_{0}\right)+\cdots+\eta^{m} d\left(y_{1}, y_{0}\right) \\
& \leq\left(\frac{\eta^{m}}{1-\eta}\right) d\left(y_{1}, y_{0}\right),
\end{aligned}
$$

which implies that $d\left(y_{n}, y_{m}\right) \rightarrow 0$ as $m, n \rightarrow \infty$ and then $\left\{y_{n}\right\}$ is a Cauchy sequence in $B$. By the completeness of $B$, the sequence $\left\{y_{n}\right\}$ converges to some $y \in B$.

Since the pair $(S, T)$ is a proximal cyclic contraction, we have

$$
d\left(x_{n+1}, y_{n+1}\right)=d\left(g x_{n+1}, g y_{n+1}\right) \leq \alpha d\left(x_{n}, y_{n}\right)+(1-\alpha) d(A, B) .
$$

We take the limit in (15) as $n \rightarrow \infty$, and it follows that

$$
d(x, y)=d(A, B)
$$

which implies that $x \in A_{0}$ and $y \in B_{0}$. It follows from $S\left(A_{0}\right) \subseteq B_{0}$ and $T\left(B_{0}\right) \subseteq A_{0}$ that there are $p \in A$ and $q \in B$ such that

$$
d(p, S x)=d(A, B)
$$

and

$$
d(q, T y)=d(A, B)
$$

From (3), (17), and the notion of a generalized proximal contraction of the first kind of $S$, we get

$$
d\left(p, g x_{n}\right) \leq \xi_{S}(x) d\left(x, x_{n-1}\right)
$$


for all $n \in \mathbf{N}$. Letting $n \rightarrow \infty$, we conclude that $p=g x$. Therefore

$$
d(g x, S x)=d(A, B)
$$

Similarly, we can show that $q=g y$ and then

$$
d(g y, T y)=d(A, B) .
$$

From (16), (20), and (21), we get

$$
d(x, y)=d(g x, S x)=d(g y, T y)=d(A, B) .
$$

For the uniqueness, let us suppose that there exist $x^{*} \in A$ and $y^{*} \in B$ such that

$$
d\left(x^{*}, y^{*}\right)=d\left(g x^{*}, S x^{*}\right)=d\left(g y^{*}, T y^{*}\right)=d(A, B) .
$$

Since $g$ is an isometry and $S$ and $T$ are generalized proximal contractions of the first kind with respect to $\left.g\right|_{A}$ and $\left.g\right|_{B}$, respectively, it follows that

$$
d\left(x, x^{*}\right)=d\left(g x, g x^{*}\right) \leq \xi_{S}(x) d\left(x, x^{*}\right)
$$

and

$$
d\left(y, y^{*}\right)=d\left(g y, g y^{*}\right) \leq \xi_{T}(y) d\left(y, y^{*}\right) .
$$

It follows from $\xi_{S}(x)$ and $\xi_{T}(y)$ being contained in $[0,1)$ that $x=x^{*}$ and $y=y^{*}$.

On the other hand, let $\left\{u_{n}\right\}$ be a sequence in $A$ and $\left\{\epsilon_{n}\right\}$ be a sequence of positive real numbers such that

$$
\lim _{n \rightarrow \infty} \epsilon_{n}=0 \quad \text { and } \quad d\left(u_{n+1}, z_{n+1}\right) \leq \epsilon_{n},
$$

where $z_{n+1} \in A$ satisfies the condition that $d\left(g z_{n+1}, S u_{n}\right)=d(A, B)$. Since $g$ is an isometry and $S$ is a generalized proximal contraction of the first kind with respect to $\left.g\right|_{A}$, we have

$$
d\left(x_{n+1}, z_{n+1}\right)=d\left(g x_{n+1}, g z_{n+1}\right) \leq \xi_{S}\left(x_{n}\right) d\left(x_{n}, u_{n}\right)
$$

and hence

$$
d\left(x_{n+1}, z_{n+1}\right) \leq M d\left(x_{n}, u_{n}\right) .
$$

Given $\epsilon>0$, we choose a positive integer $N$ such that $\epsilon_{n} \leq \epsilon$ for all $n \geq N$. For each $n \geq N$, we get

$$
\begin{aligned}
d\left(x_{n+1}, u_{n+1}\right) & \leq d\left(x_{n+1}, z_{n+1}\right)+d\left(z_{n+1}, u_{n+1}\right) \\
& \leq \operatorname{Md}\left(x_{n}, u_{n}\right)+\epsilon_{n}
\end{aligned}
$$


which implies that $d\left(x_{n+1}, u_{n+1}\right) \leq M^{n} d\left(x_{1}, x_{0}\right)+\sum_{i=1}^{n} M^{n-i} \epsilon_{i}$. Therefore, for each $n \geq N$, we have

$$
\begin{aligned}
d\left(u_{n+1}, x\right) & \leq d\left(u_{n+1}, x_{n+1}\right)+d\left(x_{n+1}, x\right) \\
& \leq M^{n} d\left(x_{1}, x_{0}\right)+\sum_{i=1}^{n} M^{n-i} \epsilon_{i}+d\left(x_{n+1}, x\right) \\
& \leq M^{n} d\left(x_{1}, x_{0}\right)+M^{n-N} \sum_{i=1}^{N} M^{N-i} \epsilon_{i}+\epsilon \sum_{i=N+1}^{n} M^{n-i}+d\left(x_{n+1}, x\right) .
\end{aligned}
$$

Letting $n \rightarrow \infty$, we have $\lim _{n \rightarrow \infty} d\left(u_{n+1}, x\right) \leq \frac{\epsilon}{1-M}$. It follows from $\epsilon>0$ being arbitrary that $\left\{u_{n}\right\}$ is convergent and it converges to $x$. This completes the proof of the theorem.

Now, we give an example to illustrate Theorem 1.

Example 3 Consider the complete metric space $\mathbf{R}^{2}$ with Euclidean metric. Let

$$
A=\{(0, y):-1 \leq y \leq 1\} \quad \text { and } \quad B=\{(1, y):-1 \leq y \leq 1\} .
$$

Define three mappings $S: A \rightarrow B, T: B \rightarrow A$, and $g: A \cup B \rightarrow A \cup B$ as follows:

$$
S(0, y)=\left(1, \frac{y^{2}}{4}\right), \quad T(1, y)=\left(0, \frac{y^{2}}{4}\right), \quad g(x, y)=(x,-y) .
$$

Then it is easy to see that $d(A, B)=1, A_{0}=A, B_{0}=B$, and the mapping $g$ is an isometry.

Next, we claim that $S$ is a generalized proximal contraction of the first kind with respect to $\left.g\right|_{A}$ and $T$ is a generalized proximal contraction of the first kind with respect to $\left.g\right|_{B}$.

Consider a function $\xi_{S}: A \rightarrow[0,1)$ defined by

$$
\xi_{S}(0, y)=\frac{|y|+1}{4} .
$$

Then $\xi_{S} \in \Xi_{S}\left(\left.g\right|_{A}\right)$. If $\left(0, y_{1}\right),\left(0, y_{2}\right) \in A$ such that

$$
d\left(a, S\left(0, y_{1}\right)\right)=d(A, B)=1 \quad \text { and } \quad d\left(b, S\left(0, y_{2}\right)\right)=d(A, B)=1
$$

for all $a, b \in A$, then we have

$$
a=\left(0, \frac{y_{1}^{2}}{4}\right), \quad b=\left(0, \frac{y_{2}^{2}}{4}\right) .
$$

Therefore, it follows that

$$
\begin{aligned}
d(a, b) & =d\left(\left(0, \frac{y_{1}^{2}}{4}\right),\left(0, \frac{y_{2}^{2}}{4}\right)\right) \\
& =\left|\frac{y_{1}^{2}}{4}-\frac{y_{2}^{2}}{4}\right| \\
& =\left(\frac{\left|y_{1}+y_{2}\right|}{4}\right)\left|y_{1}-y_{2}\right|
\end{aligned}
$$




$$
\begin{aligned}
& \leq\left(\frac{\left|y_{1}\right|+\left|y_{2}\right|}{4}\right)\left|y_{1}-y_{2}\right| \\
& \leq\left(\frac{\left|y_{1}\right|+1}{4}\right)\left|y_{1}-y_{2}\right| \\
& =\xi_{S}\left(0, y_{1}\right) d\left(\left(0, y_{1}\right),\left(0, y_{2}\right)\right) .
\end{aligned}
$$

Hence $S$ is a generalized proximal contraction of the first kind with respect to $\left.g\right|_{A}$ with the function $\xi_{S}$.

Consider a function $\xi_{T}: B \rightarrow[0,1)$ defined by

$$
\xi_{T}(1, y)=\frac{|y|+1}{4} .
$$

Then $\xi_{T} \in \Xi_{S}\left(\left.g\right|_{B}\right)$. If $\left(1, y_{1}\right),\left(1, y_{2}\right) \in B$ such that

$$
d\left(a, T\left(1, y_{1}\right)\right)=d(A, B)=1 \quad \text { and } \quad d\left(b, T\left(1, y_{2}\right)\right)=d(A, B)=1
$$

for all $a, b \in B$, then we get

$$
a=\left(1, \frac{y_{1}^{2}}{4}\right), \quad b=\left(1, \frac{y_{2}^{2}}{4}\right)
$$

Since

$$
\begin{aligned}
d(a, b) & =d\left(\left(1, \frac{y_{1}^{2}}{4}\right),\left(1, \frac{y_{2}^{2}}{4}\right)\right) \\
& =\left|\frac{y_{1}^{2}}{4}-\frac{y_{2}^{2}}{4}\right| \\
& =\left(\frac{\left|y_{1}+y_{2}\right|}{4}\right)\left|y_{1}-y_{2}\right| \\
& \leq\left(\frac{\left|y_{1}\right|+\left|y_{2}\right|}{4}\right)\left|y_{1}-y_{2}\right| \\
& \leq\left(\frac{\left|y_{1}\right|+1}{4}\right)\left|y_{1}-y_{2}\right| \\
& =\xi_{T}\left(1, y_{1}\right) d\left(\left(1, y_{1}\right),\left(1, y_{2}\right)\right),
\end{aligned}
$$

we can conclude that $T$ is a generalized proximal contraction of the first kind with respect to $\left.g\right|_{B}$ with the function $\xi_{T}$.

Moreover, the pair $(S, T)$ forms a proximal cyclic contraction and the other hypotheses of Theorem 1 are also satisfied. Further, it is easy to see that we have the unique elements $(0,0) \in A$ and $(1,0) \in B$ such that

$$
d(g(0,0), S(0,0))=d(g(1,0), T(1,0))=d((0,0),(1,0))=d(A, B) .
$$

Corollary 1 (Theorem 3.1 in [30]) Let $(X, d)$ be a complete metric space and $A$ and $B$ be nonempty, closed subsets of $X$. Further, suppose that $A_{0}$ or $B_{0}$ is nonempty. Let $S: A \rightarrow B$, $T: B \rightarrow A$, and $g: A \cup B \rightarrow A \cup B$ satisfy the following conditions: 
(a) S and T are proximal contractions of the first kind.

(b) $g$ is an isometry.

(c) The pair $(S, T)$ is a proximal cyclic contraction.

(d) $S\left(A_{0}\right) \subseteq B_{0}, T\left(B_{0}\right) \subseteq A_{0}$.

(e) $A_{0} \subseteq g\left(A_{0}\right)$ and $B_{0} \subseteq g\left(B_{0}\right)$.

Then there exists a unique point $x \in A$ and there exists a unique point $y \in B$ such that

$$
d(g x, S x)=d(g y, T y)=d(x, y)=d(A, B) .
$$

Moreover, for any fixed $x_{0} \in A_{0}$, the sequence $\left\{x_{n}\right\}$, defined by

$$
d\left(g x_{n+1}, S x_{n}\right)=d(A, B),
$$

converges to the element $x$. For any fixed $y_{0} \in B_{0}$, the sequence $\left\{y_{n}\right\}$, defined by

$$
d\left(g y_{n+1}, T y_{n}\right)=d(A, B)
$$

converges to the element $y$.

Furthermore, a sequence $\left\{u_{n}\right\}$ in A converges to $x$ if there is a sequence of positive numbers $\left\{\epsilon_{n}\right\}$ such that

$$
\lim _{n \rightarrow \infty} \epsilon_{n}=0 \quad \text { and } \quad d\left(u_{n+1}, z_{n+1}\right) \leq \epsilon_{n},
$$

where $z_{n+1} \in A$ satisfies the condition that $d\left(g z_{n+1}, S u_{n}\right)=d(A, B)$.

Proof Since a proximal contractions of the first kind is a special case of a generalized proximal contraction of the first kind, we get this result from Theorem 1.

If $g$ is assumed to be the identity mapping, then Corollary 1 yields the following best proximity point theorem.

Corollary 2 (Corollary 3.3 in [30]) Let $(X, d)$ be a complete metric space and $A$ and $B$ be nonempty, closed subsets of $X$. Further, suppose that $A_{0}$ or $B_{0}$ is nonempty. Let $S: A \rightarrow B$ and $T: B \rightarrow A$ satisfy the following conditions:

(a) $S$ and $T$ are proximal contractions of the first kind.

(b) The pair $(S, T)$ is a proximal cyclic contraction.

(c) $S\left(A_{0}\right) \subseteq B_{0}, T\left(B_{0}\right) \subseteq A_{0}$.

Then there exists $a$ unique point $x \in A$ and there exists $a$ unique point $y \in B$ such that

$$
d(x, S x)=d(y, T y)=d(x, y)=d(A, B) .
$$

Moreover, for any fixed $x_{0} \in A_{0}$, the sequence $\left\{x_{n}\right\}$, defined by

$$
d\left(x_{n+1}, S x_{n}\right)=d(A, B),
$$

converges to the element $x$. For any fixed $y_{0} \in B_{0}$, the sequence $\left\{y_{n}\right\}$, defined by

$$
d\left(y_{n+1}, T y_{n}\right)=d(A, B),
$$

converges to the element $y$. 
Furthermore, a sequence $\left\{u_{n}\right\}$ in A converges to $x$ if there is a sequence of positive numbers $\left\{\epsilon_{n}\right\}$ such that

$$
\lim _{n \rightarrow \infty} \epsilon_{n}=0 \quad \text { and } \quad d\left(u_{n+1}, z_{n+1}\right) \leq \epsilon_{n},
$$

where $z_{n+1} \in A$ satisfies the condition that $d\left(z_{n+1}, S u_{n}\right)=d(A, B)$.

Next, we establish a result for non-self-mappings which are generalized proximal contractions of the first kind and the second kind.

Theorem 2 Let $(X, d)$ be a complete metric space and $A$ and $B$ be nonempty, closed subsets of $X$. Further, suppose that $A_{0}$ or $B_{0}$ is nonempty. Let $S: A \rightarrow B$ and $g: A \rightarrow A$ satisfy the following conditions:

(a) $S$ is generalized proximal contractions of first and second kinds with respect to $g$.

(b) $g$ is an isometry.

(c) $S$ preserves isometric distance with respect to $g$.

(d) $S\left(A_{0}\right) \subseteq B_{0}$.

(e) $A_{0} \subseteq g\left(A_{0}\right)$.

Then there exists a unique point $x \in A$ such that

$$
d(g x, S x)=d(A, B) .
$$

Moreover, for any fixed $x_{0} \in A_{0}$, the sequence $\left\{x_{n}\right\}$, defined by

$$
d\left(g x_{n}, S x_{n-1}\right)=d(A, B)
$$

converges to the element $x$.

Furthermore, a sequence $\left\{u_{n}\right\}$ in A converges to $x$ if $\left\{\xi_{S}\left(x_{n}\right): n \in \mathbf{N}\right\}$ bounded with constant $M<1$ and there is a sequence of positive numbers $\left\{\epsilon_{n}\right\}$ such that

$$
\lim _{n \rightarrow \infty} \epsilon_{n}=0 \quad \text { and } \quad d\left(u_{n+1}, z_{n+1}\right) \leq \epsilon_{n}
$$

where $z_{n+1} \in A$ satisfies the condition that $d\left(g z_{n+1}, S u_{n}\right)=d(A, B)$.

Proof For fixed $x_{0} \in A_{0}$, since $S\left(A_{0}\right) \subseteq B_{0}$ and $A_{0} \subseteq g\left(A_{0}\right)$, we can construct the sequence $\left\{x_{n}\right\}$ in $A_{0}$ similarly to Theorem 1 such that

$$
d\left(g x_{n}, S x_{n-1}\right)=d(A, B)
$$

for all $n \in \mathbf{N}$. It follows from $g$ being an isometry and by virtue of the fact that we have a generalized proximal contraction of the first kind with respect to $g$ of $S$ that

$$
d\left(x_{n}, x_{n+1}\right)=d\left(g x_{n}, g x_{n+1}\right) \leq \xi_{S}\left(x_{n}\right) d\left(x_{n}, x_{n-1}\right)
$$

for all $n \in \mathbf{N}$. Similarly to the proof of Theorem 1 , we can conclude that the sequence $\left\{x_{n}\right\}$ is a Cauchy sequence in $A$ and so converges to some $x \in A$. As $S$ is a generalized proximal contraction of the second kind with respect to $g$ and preserves the isometric distance with 
respect to $g$,

$$
\begin{aligned}
d\left(S x_{n}, S x_{n+1}\right)= & d\left(S g x_{n}, S g x_{n+1}\right) \\
\leq & \xi_{S}^{\prime}\left(x_{n-1}\right) d\left(S x_{n-1}, S x_{n}\right) \\
\leq & \xi_{S}^{\prime}\left(x_{n-2}\right) d\left(S x_{n-1}, S x_{n}\right) \\
& \vdots \\
\leq & \xi_{S}^{\prime}\left(x_{0}\right) d\left(S x_{n-1}, S x_{n}\right)
\end{aligned}
$$

which implies that $\left\{S x_{n}\right\}$ is a Cauchy sequence in $B$ and then it converges to some $y \in B$. Therefore, we can conclude that

$$
d(g x, y)=\lim _{n \rightarrow \infty} d\left(g x_{n+1}, S x_{n}\right)=d(A, B),
$$

that is, $g x \in A_{0}$. Since $A_{0} \subseteq g\left(A_{0}\right)$, we have $g x=g z$ for some $z \in A_{0}$ and then $d(g x, g z)=0$. By the fact that $g$ is an isometry, we get $d(x, z)=d(g x, g z)=0$. Hence $x$ and $z$ must be identical and so $x$ becomes a point in $A_{0}$. As $S\left(A_{0}\right) \subseteq B_{0}$,

$$
d(u, S x)=d(A, B)
$$

for some $u \in A$. It follows from (25), (28), and $S$ being a generalized proximal contraction of the first kind with respect to $g$ that

$$
d\left(u, g x_{n+1}\right) \leq \xi_{S}(x) d\left(x, x_{n}\right)
$$

for all $n \in \mathbf{N}$. Taking the limit as $n \rightarrow \infty$, we see that the sequence $\left\{g x_{n}\right\}$ converges to a point $u$. Owing to the fact that $g$ is continuous, $\left\{g x_{n}\right\}$ converge to a point $g x$. By the uniqueness of the limit of the sequence, we conclude that $u=g x$. Therefore, we have the result that $d(g x, S x)=d(u, S x)=d(A, B)$. The uniqueness and the remaining part of the proof follow as in Theorem 1. This completes the proof of the theorem.

Corollary 3 (Theorem 3.4 in [30]) Let $(X, d)$ be a complete metric space and $A$ and $B$ be nonempty, closed subsets of $X$. Further, suppose that $A_{0}$ or $B_{0}$ is nonempty. Let $S: A \rightarrow B$ and $g: A \rightarrow A$ satisfy the following conditions:

(a) $S$ is proximal contractions of first and second kinds.

(b) $g$ is an isometry.

(c) $S$ preserves isometric distance with respect to $g$.

(d) $S\left(A_{0}\right) \subseteq B_{0}$.

(e) $A_{0} \subseteq g\left(A_{0}\right)$.

Then there exists a unique point $x \in A$ such that

$$
d(g x, S x)=d(A, B) .
$$

Moreover, for any fixed $x_{0} \in A_{0}$, the sequence $\left\{x_{n}\right\}$, defined by

$$
d\left(g x_{n+1}, S x_{n}\right)=d(A, B)
$$


Furthermore, a sequence $\left\{u_{n}\right\}$ in A converges to $x$ if there is a sequence of positive numbers $\left\{\epsilon_{n}\right\}$ such that

$$
\lim _{n \rightarrow \infty} \epsilon_{n}=0 \quad \text { and } \quad d\left(u_{n+1}, z_{n+1}\right) \leq \epsilon_{n}
$$

where $z_{n+1} \in A$ satisfies the condition that $d\left(g z_{n+1}, S u_{n}\right)=d(A, B)$.

Proof Since proximal contractions of the first kind and the second kind are special cases of generalized proximal contractions of the first and the second kinds, we get the result from Theorem 2 .

Corollary 4 (Corollary 3.5 in [30]) Let $(X, d)$ be a complete metric space and $A$ and $B$ be nonempty, closed subsets of $X$. Suppose that $A_{0}$ or $B_{0}$ is nonempty and $S: A \rightarrow B$ satisfy the following conditions:

(a) $S$ is proximal contractions of first and second kinds.

(b) $S\left(A_{0}\right) \subseteq B_{0}$.

Then there exists a unique point $x \in A$ such that

$$
d(x, S x)=d(A, B) .
$$

Moreover, for any fixed $x_{0} \in A_{0}$, the sequence $\left\{x_{n}\right\}$, defined by

$$
d\left(x_{n+1}, S x_{n}\right)=d(A, B),
$$

converges to the element $x$.

Furthermore, a sequence $\left\{u_{n}\right\}$ in A converges to $x$ if there is a sequence of positive numbers $\left\{\epsilon_{n}\right\}$ such that

$$
\lim _{n \rightarrow \infty} \epsilon_{n}=0 \quad \text { and } \quad d\left(u_{n+1}, z_{n+1}\right) \leq \epsilon_{n}
$$

where $z_{n+1} \in A$ satisfies the condition that $d\left(z_{n+1}, S u_{n}\right)=d(A, B)$.

\section{Competing interests}

The authors declare that they have no competing interests.

Authors' contributions

All authors contributed equally to the writing of this paper. All authors read and approved the final manuscript.

\section{Acknowledgements}

The first author would like to thank the Thailand Research Fund and Thammasat University under Grant No. TRG5780013 for financial support during the preparation of this manuscript. The second author was supported by the Higher Education Research Promotion and National Research University Project of Thailand.

Received: 17 August 2014 Accepted: 15 October 2014 Published: 04 Nov 2014

\section{References}

1. An, TV, Dung, NV, Kadelburg, Z, Radenović, S: Various generalizations of metric spaces and fixed point theorems. Rev. R. Acad. Cienc. Exactas Fís. Nat., Ser. A Mat. (2014). doi:10.1007/s13398-014-0173-7

2. Roshan, JR, Shobkolaei, N, Sedhi, S, Parvaneh, V, Radenović, S: Common fixed point theorems for three maps in discontinuous $G_{b}$-metric spaces. Acta Math. Sci. Ser. B 34(5), 1-12 (2014)

3. Ćojbašić Rajić, V, Radenović, S, Chauhan, S: Common fixed point of generalized weakly contractive maps in partial metric spaces. Acta Math. Sci. Ser. B 34(4), 1345-1356 (2014) 
4. Alsulami, HH, Roldan, A, Karapinar, E, Radenović, S: Some inevitable remarks on 'Tripled fixed point theorems for mixed monotone Kannan type contractive mappings'. J. Appl. Math. 2014, Article ID 392301 (2014)

5. Fan, K: Extensions of two fixed point theorems of F.E. Browder. Math. Z. 112, 234-240 (1969)

6. Prolla, JB: Fixed point theorems for set-valued mappings and existence of best approximations. Numer. Funct. Anal. Optim. 5, 449-455 (1982/83)

7. Reich, S: Approximate selections, best approximations, fixed points and invariant sets. J. Math. Anal. Appl. 62, 104-113 (1978)

8. Sehgal, VM, Singh, SP: A generalization to multifunctions of Fan's best approximation theorem. Proc. Am. Math. Soc $102,534-537(1988)$

9. Sehgal, VM, Singh, SP: A theorem on best approximations. Numer. Funct. Anal. Optim. 10, 181-184 (1989)

10. Al-Thagafi, MA, Shahzad, N: Best proximity pairs and equilibrium pairs for Kakutani multimaps. Nonlinear Anal. 70(3), 1209-1216 (2009)

11. Al-Thagafi, MA, Shahzad, N: Best proximity sets and equilibrium pairs for a finite family of multimaps. Fixed Point Theory Appl. 2008, Article ID 457069 (2008)

12. Kim, WK, Kum, S, Lee, KH: On general best proximity pairs and equilibrium pairs in free abstract economies. Nonlinear Anal. 68(8), 2216-2227 (2008)

13. Kirk, WA, Reich, S, Veeramani, P: Proximinal retracts and best proximity pair theorems. Numer. Funct. Anal. Optim. 24 851-862 (2003)

14. Sadiq Basha, S, Veeramani, P: Best approximations and best proximity pairs. Acta Sci. Math. 63, 289-300 (1997)

15. Sadiq Basha, S, Veeramani, P: Best proximity pair theorems for multifunctions with open fibres. J. Approx. Theory 103, 119-129 (2000)

16. Sadiq Basha, S, Veeramani, P, Pai, DV: Best proximity pair theorems. Indian J. Pure Appl. Math. 32, 1237-1246 (2001)

17. Srinivasan, PS: Best proximity pair theorems. Acta Sci. Math. 67, 421-429 (2001)

18. Wlodarczyk, K, Plebaniak, R, Banach, A: Best proximity points for cyclic and noncyclic set-valued relatively quasi-asymptotic contractions in uniform spaces. Nonlinear Anal. 70(9), 3332-3341 (2009)

19. Wlodarczyk, K, Plebaniak, R, Banach, A: Erratum to: 'Best proximity points for cyclic and noncyclic set-valued relatively quasi-asymptotic contractions in uniform spaces.' Nonlinear Anal. 71, 3583-3586 (2009)

20. Wlodarczyk, K, Plebaniak, R, Obczynski, C: Convergence theorems, best approximation and best proximity for set-valued dynamic systems of relatively quasi-asymptotic contractions in cone uniform spaces. Nonlinear Anal. 72, 794-805 (2010)

21. Radenović, S, Kadelburg, Z: A note on some recent best proximity point results for non-self mappings. Gulf J. Math. 1 36-41 (2013)

22. Raj, VS: A best proximity point theorem for weakly contractive non-self-mappings. Nonlinear Anal. 74, 4804-4808 (2011)

23. Kumam, P, Roldán-López-de-Hierro, AF: On existence and uniqueness of $g$-best proximity points under $(\varphi, \theta, \alpha, g)$-contractivity conditions and consequences. Abstr. Appl. Anal. 2014, Article ID 234027 (2014)

24. Mongkolkeha, C, Cho, YJ, Kumam, P: Best proximity points for generalized proximal C-contraction mappings in metric spaces with partial orders. J. Inequal. Appl. 2013, 94 (2013)

25. Mongkolkeha, C, Cho, YJ, Kumam, P: Best proximity points for Geraghty's proximal contraction mappings. Fixed Point Theory Appl. 2013, 180 (2013)

26. Kumam, P, Aydi, H, Karapinar, E, Sintunavarat, W: Best proximity points and extension of Mizoguchi-Takahashi's fixed point theorems. Fixed Point Theory Appl. 2013, 242 (2013)

27. Sintunavarat, W, Kumam, P: The existence theorems of an optimal approximate solution for generalized proximal contraction mappings. Abstr. Appl. Anal. 2013, Article ID 375604 (2013)

28. Karapinar, E, Sintunavarat, W: The existence of optimal approximate solution theorems for generalized $\alpha$-proximal contraction non-self mappings and applications. Fixed Point Theory Appl. 2013, 323 (2013)

29. Kutbi, MA, Chandok, S, Sintunavarat, W: Optimal solutions for nonlinear proximal $C_{N}$-contraction mapping in metric space. J. Inequal. Appl. 2014, 193 (2014)

30. Sadiq Basha, S: Best proximity point theorems generalizing the contraction principle. Nonlinear Anal. 74, 5844-5850 (2011)

10.1186/1687-1812-2014-228

Cite this article as: Sintunavarat and Kumam: The existence and convergence of best proximity points for generalized proximal contraction mappings. Fixed Point Theory and Applications 2014, 2014:228

\section{Submit your manuscript to a SpringerOpen ${ }^{\odot}$ journal and benefit from:}

- Convenient online submission

- Rigorous peer review

- Immediate publication on acceptance

- Open access: articles freely available online

- High visibility within the field

- Retaining the copyright to your article

Submit your next manuscript at $>$ springeropen.com 